\title{
Isolation, Screening and Molecular Characterization of Multifunctional Plant Growth Promoting Rhizobacteria for a Sustainable Agriculture
}

\author{
Kay Thi Oo'1,2, Theint Theint Win'1,2, Aye Aye Khai1,2, Pengcheng Fu1 ${ }^{*}$ \\ ${ }^{1}$ State Key Laboratory of Marine Resource Utilization in South China Sea, Hainan University, Haikou, China \\ ${ }^{2}$ Biotechnology Research Department, Department of Research and Innovation, Union of Myanmar Ministry of Education, \\ Kyaukse Township, Mandalay Region, Myanmar \\ Email: *pcfu@hainanu.edu.cn
}

How to cite this paper: Oo, K.T., Win, T.T., Khai, A.A. and Fu, P.C. (2020) Isolation, Screening and Molecular Characterization of Multifunctional Plant Growth Promoting Rhizobacteria for a Sustainable Agriculture. American Journal of Plant Sciences, 11, 773-792.

https://doi.org/10.4236/ajps.2020.116055

Received: May 10, 2019

Accepted: June 19, 2020

Published: June 22, 2020

Copyright $\odot 2020$ by author(s) and Scientific Research Publishing Inc. This work is licensed under the Creative Commons Attribution International License (CC BY 4.0).

http://creativecommons.org/licenses/by/4.0/

\section{(c) (i) Open Access}

\begin{abstract}
The use of PGPR as a multifunctional biofertilizer or biostimulant is an alternative way to prevent soil pollution and preserve agricultural for sustainable economy. In this study, 102 bacterial strains were isolated from rhizospheric soil of different crop fields. Among them, 15 bacterial isolates rich of NPK were selected to screen for PGP activity. It was found that 4 out 15 isolates were able to fix atmospheric nitrogen, 14 could solubilize phosphate and 5 could solubilize potassium. They were further examined for the production of hydrolytic enzymes (amylase, cellulose, chitinase, etc.), plant hormone (IAA) and plant defense substances (HCN, siderophore, etc.). All PGPR isolates were able to produce IAA, siderophore and ammonia while 2 isolates could produce HCN. Among them, 73.33\% of selected isolates produced amylase, $80 \%$ produced cellulase, $66.67 \%$ produced pectinase, $93.33 \%$ produced chitinase and $\beta$-glucanase. For salt stress tolerance, all the isolates grew well in $5 \% \mathrm{NaCl}$ while only 4 tolerated $9 \% \mathrm{NaCl}$. Among all isolates, 2 have antifungal activity and 5 have antibacterial activity. The best 6 isolates and consortium were tested to promote plant growth in green-gram and maize germination. Seed germination of green-gram and maize was observed the best in Acromobacter insolitus S3 compared with other treatments. Pseudomonas plecoglossicida B3 was found the best in fresh weight for both crops. The highest root formation was observed in Acromobacter insolitus $\mathrm{S} 3$ treatment in maize and Enterobacter hormaechei W1 treatment in green-gram.
\end{abstract}




\section{Keywords}

PGPR, Rhizobacteria, Maize, Green-Gram, Siderophore, IAA

\section{Introduction}

The increasing human population is exerting immense pressure on agricultural lands for the need of higher crop production. It results in ever increasing use of chemical fertilizers all over the world. However, fertilizer overuse has triggered soil infertility due to continuous deposition of chemical residues, increasing soil acidity, decreasing biological activities, altered soil physical characteristics and diminished microelements [1]. Chemical fertilizers are expensive with many limitations such as leaching, pollution of water resources, upset of beneficial microbial ecosystems, and release of green-house gases. Consequently, environmentally friendly agricultural practices have been recently arisen as a renewed approach [2].

Microorganisms have a vital role in agriculture by promoting the supply of plant nutrients to reduce the use of chemical fertilizers. Biofertilizers using microorganisms could be highly beneficial as a successful way of microbial stimulants in agriculture with their multiple plant growth activities [3]. Rhizosphere is a unique locus in association with various groups of microorganisms which have the capacity to influence plant growth. These beneficial plant-microbe interactions in the rhizosphere can thus enhance soil fertility [4]. Combinations of microbial community with plant roots are complex and enable plants to obtain required nutrients from the soil through a number of mechanisms. However, in the rhizosphere, only $1 \%-2 \%$ of bacteria can promote plant growth [5]. Bacteria that colonize in the rhizosphere to stimulate plant growth directly or indirectly are referred to as plant growth promoting rhizobacteria (PGPR). There are about thirteen mineral nutrients in the soil that are classified as macronutrient elements and micronutrient elements [6]. Plants need the right combination for their nutritional needs to live, to grow and to reproduce [7]. These minerals are dissolved and absorbed through the plant root system. However, the amounts of nutrients in the soil are always unpredictable and may not be enough for plant growth [8].

Biofertilizers using beneficial microbes can be applied to seed, root, and soil for the NPK availability and to build up the microflora for the improvement of soil health. Different microbes have been used to meet nutrient requirements in the soil. For example, $\mathrm{N}$-fixer microbes can be used to supply nitrogen by converting the nitrogen from the atmosphere into ammonium ion for plants' uptake. Likewise, phosphorus solubilizer in the biofertilizers can be applied to convert phosphorus in the soil and rock into phosphate ion [9]. Mechanisms of nitrogen fixation, phosphate solubilisation and auxin production have been well studied. However, mechanisms of plant growth interacted with soil microbiota 
have yet to be investigated in depth. In particular, the production of siderophores ( $\mathrm{Fe}^{3+}$ binding agents) involves the preventing of harmful effects by phytopathogens should be assessed. For example, plant pathogen inhibition includes production of ammonia, hydrogen cyanide and chitinases while ammonia involves in the nitrogen supply for plants. Microbes in rhizosphere may produce important extracellular enzymes such as pectinases and cellulases [10]. Production of extracellular enzymes to enhance plant resistance to biotic and abiotic stress have been reported through the use of plant growth promoting rhizobacteria [11]. This study aimed at the selection of multifunctional PGPRs from soil samples of crop lands to determine highest number of plant growth promoting traits. 102 bacterial strains were isolated from rhizospheric soil of different crop fields in Hainan and Anhui Provinces, China. The potential PGPR isolates would be evaluated for their ability to promote the growth of green-gram and maize.

\section{Materials and Methods}

Soil Sample Collection. Soil samples were collected from the rhizospheric soils of five different crop cultivated areas (kidney bean, rice, sugarcane, tomato and watermelon) in Hainan Province and four different crop cultivated areas (maize, soybean, tomato and watermelon) in Anhui Province, China.

Bacterial Isolation. Soil microbes were isolated from each sample by serial dilution and spread plate method. $0.1 \mathrm{~g}$ of soil sample was dispersed in $900 \mu \mathrm{l}$ of sterilized $\mathrm{NaCl}(0.9 \%)$ and was thoroughly shaken using vortex mixer. $100 \mu \mathrm{l}$ of the above solution was transferred to $900 \mu \mathrm{l}$ of sterile to form $10^{1}$ dilution. Similarly $10^{2}, 10^{3}, 10^{4}, 10^{5}$ and $10^{6}$ serials were made for each soil sample. $100 \mu \mathrm{l}$ of each dilution was spread on Burks' $\mathrm{N}$ free medium at $30^{\circ} \mathrm{C} \pm 1^{\circ} \mathrm{C}$ for $48 \mathrm{hrs}$ (NFB isolation), on Pikovskaya's [12] agar medium (PVK) containing insoluble Tricalcium phosphate. It was incubated at $30^{\circ} \mathrm{C} \pm 1^{\circ} \mathrm{C}$ for $48 \mathrm{hrs}$ (PSB isolation) with Aleksandrow's medium at $30^{\circ} \mathrm{C} \pm 1{ }^{\circ} \mathrm{C}$ for 7 days (for KSB isolation). Different colonies on the media were picked and purified by subculture method on respective agar media to get the pure colonies.

Preservation of the PGPR Isolates. After growing the isolated bacteria (PSB, NFB and KSB) in LB broth, add $500 \mu \mathrm{L}$ of the overnight culture to $500 \mu \mathrm{L}$ of $50 \%$ glycerol in a $2 \mathrm{~mL}$ screw top tube. They were freezed in the glycerol stock tubes at $-80^{\circ} \mathrm{C}$.

Bacterial cultures were centrifuged at $10,000 \mathrm{rpm}$ for $10 \mathrm{mins}$. The cell pellets were washed with phosphate buffer by centrifugation at 10,000 rpm for 10 mins. They were then mixed thoroughly with $15 \%$ skim milk and $15 \%$ rice powder by vortexing. Finally, the bacterial broth in skim milk and rice powder were subjected to lyophilizer for $48 \mathrm{hrs}$ (Figure 2).

In Vitro Screening of Bacterial Isolates for their Potential Plant Growth Promoting Traits

Phosphate Solubilization Activity. All the colonies from the isolation media 
were screened for phosphate solubilization on Pikovskaya's medium. All the Isolates were spot inoculated at the centre of Pikovskaya's plate and incubated at $37^{\circ} \mathrm{C}$. Diameter of clear zone was measured successively after 5 days of the culture incubation by Phosphate Solubilization Efficiency (PSE) approach which measures the ratio of total diameter, i.e. clearance zone including bacterial growth and the colony diameter. Formula of phosphate solubilization index: PSI $=$ Colony diameter + Halozone diameter/Colony diameter. Strains would develop clear zones around their colonies could easily identify as PSM.

Nitrogen Fixing Activity. The visual detection of nitrogen fixing activity was observed using Nitrogen Free Mineral Medium (NFMM) with 2\% Glucose and trace amount of BTB. The isolated bacteria were spot inoculated and streaked on the above media. After 3 to 10 days incubation, the color changing of the medium from green to blue was recorded.

Potassium Solubilization Activity. All the KSB isolates were screened for potassium solubilization on Aleksandrow's medium. The isolates were spot inoculated at the center of Aleksandrow's media plates and incubated at $37^{\circ} \mathrm{C}$. Diameter of clear zone was measured successively after 4 weeks.

Qualitative and Quantitative Estimation of Plant Growth Hormone (IAA) Production Activity. Bacterial isolates were inoculated in sterilized nutrient broth supplemented with $1 \%$ tryptophan (precursor for IAA production) and then incubated on shaker for 7 days at $28^{\circ} \mathrm{C}-30^{\circ} \mathrm{C}$. After incubation period, the cultures were centrifuged at $10,000 \mathrm{rpm}$ for 10 mins. $1 \mathrm{ml}$ of each supernatant was mixed with $2 \mathrm{ml}$ Salkowski reagent $\left(1 \mathrm{ml}\right.$ of $0.5 \mathrm{M} \mathrm{FeCl}_{3}$ in $50 \mathrm{~mL}$ of $35 \%$ $\mathrm{HClO}_{4}$ ). The mixtures were left at room temperature for 30 mins. Development of pink color indicated the production of IAA and the quantification of IAA was read at $530 \mathrm{~nm}$ in UV-Vis spectrophotometer.

A standard curve was plotted for quantification of IAA solution and uninoculated medium with a reagent serves as a control. The amount of IAA in the culture was expressed as $\mu \mathrm{g} / \mathrm{ml}$ [13]. Standard solution was made in nutrient medium at $0,5,10,20,50$, and $100 \mu \mathrm{g} / \mathrm{ml}(\mathrm{ppm})$. In a glass beaker of $10 \mathrm{ml}$ acetone in the fume hood, $10 \mathrm{mg}$ IAA was added and stirred with metal spatula until IAA was completely dissolved. It was the $1000 \mu \mathrm{g} / \mathrm{ml}$ stock which was labeled with a series of amber vials with the dilution series.

The solution was incubated at room temperature for 30 mins to read with UV-Vis spectrophotometer at the OD530. The color difference across the gradient of concentrations was observed in a few minutes. The absorbance was recorded into an Excel spreadsheet. The amounts of IAA produced by bacterial isolates were calculated using the standard curve prepared with known IAA concentrations.

Production of Ammonia. Bacterial isolates were tested for the production of ammonia (in terms of nitrogen fixing activity) in peptone water. Freshly grown cultures were inoculated in $10 \mathrm{ml}$ peptone water in each tube separately and incubated on a rotary shaker for $96 \mathrm{hrs}$ at $28^{\circ} \mathrm{C} \pm 2^{\circ} \mathrm{C}$. After incubation, Nesseler's reagent $(0.5 \mathrm{ml})$ was added in each tube. Development of faint yellow color in- 
dicates small amounts of ammonia and deep yellow to brownish color indicates maximum amount of ammonia production [14].

$50 \mathrm{~g}$ of KI was dissolved in the smallest possible quantity of cold water (50 $\mathrm{ml})$. A saturated solution of mercuric chloride was added until the formation of a precipitate. Then $200 \mathrm{ml}$ of $5 \mathrm{~N} \mathrm{NaOH}$ was added to dilute to $1 \mathrm{~L}$.

In Vitro Screening of Bacterial Isolates for their Biocontrol Properties

Screening for Hydrogen Cyanide (HCN) Production Activity. HCN production assay was evaluated by streaking the bacterial isolates on Nutrient agar medium amended with glycine (NB $18 \mathrm{~g} / \mathrm{l}+$ Agar $15 \mathrm{~g} / \mathrm{l}+$ glycine $4.4 \mathrm{~g} / \mathrm{l}$ ). Feigl-Anger paper was placed in the lid of each Petri plate. The plates were then sealed air-tight with Para film or wrapping plastic and incubated at $30^{\circ} \mathrm{C}$ for 48 hrs. A color change of the filter paper from faint blue green to bright blue color was considered as an indication of HCN production.

Filter paper strips were prepared by dipping the filter paper strips for 2 mins in a 1:1 mixture of two freshly prepared solutions: 1) $1 \%(\mathrm{w} / \mathrm{v})$ methylenebis in chloroform and 2) 1\% (w/v) copper ethyl acetoacetate in chloroform. The dried papers were wrapped with aluminium foil and then put inside the plastic bag until used. The Feigl-Anger paper turned from a faint blue green to a bright blue in the presence of HCN; they will detect as little as $1 \mu \mathrm{g} \mathrm{HCN}$.

Screening for Siderophore Production Activity. For the detection of siderophore production by microorganisms in solid medium, the universal chrome azurol S (CAS) -agar plate assay was used [15].

The bacterial cultures were spot inoculated on CAS agar medium and were incubated at $28^{\circ} \mathrm{C}$ for four days. The siderophore producing bacterial colonies showed orange color around the colony. The CAS assay is based on siderophore ability to bind to ferric iron with high affinity. The agar contains Chrome Azurol $\mathrm{S}$ (CAS) dye which, when complexed with $\mathrm{Fe}^{3+}$, was blue in color.

Screening for Hydrolytic Enzyme Production Activity

Amylase Enzyme Production Activity. Starch hydrolysis test was done for screening of amylase producing bacteria. Bacterial isolates were spot inoculated on the starch agar medium plates and incubated at $28^{\circ} \mathrm{C}$ for 7 days. After incubation Iodine solution was flooded in the plates with the help of dropper. The plates were then kept undisturbed for 5 - 10 minutes while the iodine solution was discarded from the plates. The clear halo around the colony indicates the production of amylase from the bacterial isolates [16].

Pectinase Enzyme Production Activity. The screening of Pectin degrading enzymes was done by inoculating of the isolates in pectin amended nutrient medium. The plates were incubated at $28^{\circ} \mathrm{C}$ for 7 days. After incubation period, the plates were flooded with $1 \%$ Congo red solution. They were washed with $1 \mathrm{M}$ $\mathrm{NaCl}$ solution in order to remove superficially adhered congo-red dye. The isolates producing pectinase indicated the appearance of clear halo zone around the colonies according to Anand et al. [17].

Cellulase Enzyme Production Activity. Cellulase production was determined by using the method of Wood et al. The isolates were spot inoculated into 
the medium containing $\mathrm{NaNO}_{3} 1 \mathrm{~g}, \mathrm{~K}_{2} \mathrm{HPO}_{4} 1 \mathrm{~g}, \mathrm{KCl} 1 \mathrm{~g}, \mathrm{MgSO}_{4} 0.5 \mathrm{~g}, \mathrm{FeSO}_{4}$ $0.01 \mathrm{~g}$, yeast extract $5 \mathrm{~g}$, Agar $15 \mathrm{~g}$, carboxy methyl cellulose (CMC) $2 \mathrm{~g}$ and incubated for 2 days at $28^{\circ} \mathrm{C}$. After cell growth, the presence of extracellular cellulase was detected by flooding the plates with $1 \%$ Congo red solution for $15 \mathrm{mi}$ nutes. The plates were destained with $1 \mathrm{M} \mathrm{NaCl}$ for 15 minutes. They were then visualized for halo zone indicating cellulase production [18].

$\beta$-Glucanase Enzyme Production Activity. $\beta$-1,3-glucanase detection was tested in agar containing nutrient media with $0.01 \%$ laminarin. Microorganisms were spot inoculated and incubated at $28^{\circ} \mathrm{C}$. Laminarin depolymerized zones were seen on the culture plates after 5 days.

Chitinase Enzyme Production Activity. Colloidal chitin was made by slowly adding chitin powder to $10 \mathrm{M} \mathrm{HCl}$ with vigorous stirring and kept overnight at $4^{\circ} \mathrm{C}$ in the refrigerator. This suspension was added to chilled ethanol with stirring vigorously and kept overnight at $25^{\circ} \mathrm{C}$. Then, the precipitate was collected by centrifugation at $10,000 \mathrm{rpm}$ for 20 mins, washed with sterile distilled water until colloidal chitin became neutral $\mathrm{pH}$. Finally it was stored at $4^{\circ} \mathrm{C}$ until further use [19].

Basal chitinase detection medium was directly supplemented with colloidal chitin $(4.5 \mathrm{~g} / \mathrm{l})$ and bromocresol purple $(0.15 \mathrm{~g} / \mathrm{l})$. Resulting substrate had a bright yellow-color, and retained enough bromocresol purple even after $\mathrm{pH}$ was adjusted to 4.7 and sterilization at $121^{\circ} \mathrm{C}$ for 15 mins. Colloidal chitin media containing bromocresol purple ( $\mathrm{pH} 4.7$ ) were inoculated with chitinolytic bacterial isolates, resulted in breakdown of chitin into $\mathrm{N}$-acetyl glucosamine.

Screening for Salt tolerance Activity. The selected bacterial strains were screened for salt tolerance ability as abiotic tolerance activity by spot inoculating the isolates on nutrient agar plates containing different concentrations of $\mathrm{NaCl}$ $(1 \%, 2 \%, 3 \%, 4 \%, 5 \%, 6 \%, 7 \%, 8 \%$ and $9 \%)$. They were incubated at $32^{\circ} \mathrm{C}$ for 5 days.

Antibacterial Activity against Xanthomonas campestric. All the selected 15 bacterial isolates were cultured in LB medium at $30^{\circ} \mathrm{C}$ for $72 \mathrm{hr}$ under agitation. The cell free supernatant was obtained by centrifugation $(10,000 \mathrm{rpm} \times 10 \mathrm{~min}$.) and filtered through a $0.45 \mu \mathrm{m}$ Millipore filter. The well diffusion method was used to determine the antimicrobial activities of the isolates. The $50 \mu \mathrm{l}$ of filtrate were dropped in the well $\left(0.6 \mathrm{~cm}\right.$.) on nutrient agar which contained about $10^{8}$ $\mathrm{CFU} / \mathrm{ml}$ of Xanthomonas campestris in upper layer. The plates were incubated at $30^{\circ} \mathrm{C}$ for $48 \mathrm{hr}$. The antibacterial activity was determined by measurement of the diameter of clear zone.

Antifungal Activity against Phythium sp., Rhizoctonia solani and Fusarium oxisporum in Dual Culture Plate Method. All the selected isolates were screened for antifungal activities against Fusarium oxysporum, Rhizoctonia solani and Phythium sp. by using Potato Dextrose Agar (PDA) medium. The isolates were spot inoculated on PDA medium $3 \mathrm{~cm}$ in distance opposite to pathogenic fungi inoculated at the other side of the medium. The zone between isolates and fungi indicated antagonist interaction between them. Antagonist activ- 
ity was investigated for 4 to 7 days after incubation at $28^{\circ} \mathrm{C}$ in the incubator.

\section{Molecular Characterization of Selected Bacterial Isolates Based on 16s} rRNA Gene Sequence Analysis. Bacterial identification was initially performed using gram staining reactions and examined by electron microscope. Then, molecular identification of the isolates was determined on the basis of $16 \mathrm{~S}$ rDNA sequence analysis. Bacterial isolates were cultured for $48 \mathrm{hrs}$ and the DNA of the isolates was extracted according to the procedure described by Sambrook et al. [20]. The extracted bacterial genomic DNA was visualized in 1\% agarose gel electrophoresis prestained with ethidium bromide at $100 \mathrm{~V}$ for 45 minutes and the DNA was viewed under UV light and stored at $-20^{\circ} \mathrm{C}$ for further use.

DNA template for PCR amplification was prepared by picking individual colony of each strain and amplification of $16 \mathrm{~S}$ rRNA gene. Amplification of the gene was carried out by PCR using 27F (5-AGAGTTTGATCTTGGCTCAG-3) and 1492R (5-GGT TAC CTT GTT ACG ACT T-3) universal primers according to Turner et al. [8]. Reaction mixture $(25 \mu \mathrm{L})$, prepared for full-length $16 \mathrm{~S}$ rRNA gene amplification was initially denatured at $94^{\circ} \mathrm{C}$ for $2 \mathrm{~min}$, followed by 30 cycles consisting of denaturation at $94^{\circ} \mathrm{C}$ for $1 \mathrm{~min}$; primer annealing at $52^{\circ} \mathrm{C}$ for 1:30 min. and primer extension at $72^{\circ} \mathrm{C}$ for $2 \mathrm{~min}$ and finally extension at $72^{\circ} \mathrm{C}$ for $10 \mathrm{~min}$ in a thermal cycler. Amplified PCR products of $16 \mathrm{~S}$ ribosomal gene were separated on $1 \%$ agarose gel in $0.5 \mathrm{X}$ TE (Tris-EDTA) buffer containing 2 $\mu \mathrm{L}$ ethidium bromide $(20 \mathrm{mg} / \mathrm{mL}) . \lambda$ Hind-III ladder was used as a size marker. The gel was viewed under UV light and photographed using gel documentation system. Amplified PCR products of full length 16S rRNA genes were sent to the sequencing company with the service of PCR purification. After receiving the sequences for individual isolates, these $16 \mathrm{rDNA}$ sequences were conducted by using the BLASTN program from NCBI web site (http://www.ncbi.nlm.nih.gov).

Seed Germination Bioassay of Selected Bacterial Isolates on Green-gram and Maize. The seeds of green-gram and maize were used for germination assay in plant growth chamber. All the selected seeds were surface sterilized by $1 \%$ $\mathrm{NaOCl}$ for 90 seconds followed by 30 seconds in $70 \%$ ethanol and two consecutive rinses in sterile distilled water, followed by air drying under laminar air flow condition [21]. Bacterial inoculum was prepared by collecting bacterial cells from $48 \mathrm{hrs}$ old culture and was diluted to adjust $10^{8} \mathrm{cfu} / \mathrm{ml}$ bacterial solutions with sterile distilled water. Seeds were coated with culture by immersion in a suspension of bacteria for 30 mins. They were then dried in a laminar flow cabinet for 1 to $2 \mathrm{hr}$. This experiment was carried out in three replications and the results were compared with control seeds treated with water instead of a bacterial isolate. Fifty seeds treated with bacteria and water was placed in sterile Petri-dish and was incubated for 4 days in plant growth chamber. Germinated seeds were counted at day 4 . The average seedling lengths for each plant were also recorded for calculation of the vigour index. Vigour index (VI) was calculated by VI $=(R L+S L) \times P G[22]$. And the average fresh weighs and number of root of the plants treated by each bacterial isolates, bacterial consortium, positive 
and negative controls were also recorded.

Statistical Analysis. All the experiments for germination analyses were performed in triplicate. Appropriate controls such as positive control and negative control were also included. The data collected were statistically analyzed using a completely randomized design in the case of the petriplate experiment. The means were compared using a least significant difference test. The correlation coefficients between a pair of trait were determined and the significance of the correlation determined using ANOVA. All the statistical tests were performed at $\alpha<0.05$.

\section{Results and Discussion}

The novel plant growth promoting bacteria were used as biofertilizers, biopesticides and phytostimulants for the improvement of nutrient solubility, fruit quality and soil fertility. Rhizospheric soil samples 4 from Anhui Province and 5 from Hainan Province were used for the isolation of PGPR with multiple effective plant growth promoting traits. The PGPR would produce a variety of regulatory chemicals in the vicinity of rhizosphere [23] to improve plant growth and to protect them from disease and abiotic stress. The bacterial population in different fields in Hainan and Anhui Provinces were recorded by using serial dilution methods of the respective soil samples. The highest population of NFB isolates $\left(2.3 \times 10^{6} \mathrm{cfu}\right)$ was found in a tomato field from Anhui Province, the highest PSB population $\left(4.6 \times 10^{6} \mathrm{cfu}\right)$ was found in a watermelon field from Anhui Province and the highest KSB population was found in another watermelon field from Hainan Province (Table 1). The attempts yielded the isolates of PSB (27), NFB (43) and KSB (32) in total (Table 2). All the 102 isolates were further screened on the respective media for their NPK activities. Among them, 15 strains with dual effects such as phosphate solubilization, nitrogen fixing and/or potassium solubilization were selected for further investigation of plant growth promoting activities such as IAA production, hydrolytic enzyme production and defence substances production. According to the screening results, 6 most prominent isolates were identified with their $16 \mathrm{~s}$ rRNA gene sequences. For germination assay analysis, the best 6 PGPR isolates were tested both individually and in combination as a consortium on green-gram and maize crops for plate germination bioassay.

Plant Growth Promoting Activities of the Isolates. Nitrogen fixing activity is an important criterion for the selection of potential PGPR. Plants are seen to achieve their optimal growth when they obtain enough amount of required nutrients such as nitrogen with the presence of N-fixing PGPRs [24]. Their nitrogen fixing ability is determined by the strain screening on nitrogen free minimum medium (NFMM). Among 43 isolated strains, only 10 have showed satisfactory results on nitrogen fixing activity by changing the culture color from green to blue. The strains with color changed were B2, B3, B5, S2, S3, S4, T1, T4, WA4 and WA6. (Table 3) Among them, B3, S2, S3 and S4 strains indicated the best nitrogen fixing activities and phosphate solubilizing activities. 
Phosphorus is one of the macronutrients essentially required for plant growth and development. A plenty of phosphorus is basically available in the soil due to previous overuse of various chemical fertilizers in an insoluble mineral form. Phosphate solubilizing bacteria (PSB) play an important role to solubilize such insoluble phosphates into soluble forms for the plants to use. PSB has been considered as one of the best alternatives for the production of inorganic phosphate biofertilizers to improve plant growth and yield [6]. The selected bacterial strains were identified as potential phosphate solubilizers based on screening of their solubilizing activities by the formation of clear zone around the colonies on $\mathrm{Pi}$ kovskaya's agar plates. Among all 27 PSB isolates, the best strains were M1, M2, BP2, BP3, W1 and W5 base on their PSI value (Table 3).

Table 1. Population Status of PSB, NFB and KSB from Different Crop Fields in Hainan and Anhui Province of respective fields.

\begin{tabular}{cccc}
\hline \multirow{2}{*}{ Soil samples (crop fields) } & \multicolumn{3}{c}{ Rhizospheric microbes } \\
\cline { 2 - 3 } Bean (B), Hainan & (PSB) c.f.u & (NFB) c.f.u & (KSB) c.f.u \\
Rice (R), Hainan & $3.9 \times 10^{4}$ & $1.1 \times 10^{5}$ & - \\
Sugarcane (S), Hainan & $3.9 \times 10^{5}$ & $2.4 \times 10^{5}$ & $1.1 \times 10^{5}$ \\
Tomato (T), Hainan & $6.1 \times 10^{5}$ & $1.8 \times 10^{5}$ & $2.3 \times 10^{6}$ \\
Watermelon (W), Hainan & $5.1 \times 10^{5}$ & $2.8 \times 10^{5}$ & $1.2 \times 10^{5}$ \\
Soybean (SA), Anhui & $2.5 \times 10^{5}$ & $8 \times 10^{4}$ & $4.6 \times 10^{6^{*}}$ \\
Maize (MA), Anhui & $7.4 \times 10^{6}$ & $1.2 \times 10^{5}$ & $2.2 \times 10^{6}$ \\
Tomato (TA), Anhui & $3.3 \times 10^{6}$ & $1.3 \times 10^{6}$ & $8 \times 10^{5}$ \\
Watermelon (WA), Anhui & $1.6 \times 10^{7}$ & $2.3 \times 10^{6 *}$ & - \\
\hline
\end{tabular}

* means highest population.

Table 2. Potential PGPR isolates from the respective fields.

\begin{tabular}{cccc}
\hline \multirow{2}{*}{ Soil samples (crop fields) } & \multicolumn{3}{c}{ Rhizospheric microbes } \\
\cline { 2 - 4 } Bean (B), Hainan & (PSB) & (NFB) & (KSB) \\
Rice (R), Hainan & 3 & 8 & - \\
Sugarcane (S), Hainan & 3 & 3 & 3 \\
Tomato (T), Hainan & 1 & 3 & 7 \\
Watermelon (W), Hainan & 4 & 7 & 7 \\
Soybean (SA), Anhui & 3 & - & 6 \\
Maize (MA), Anhui & 3 & 4 & 5 \\
Tomato (TA), Anhui & 6 & 5 & - \\
Watermelon (WA), Anhui & 1 & 7 & - \\
Total & 3 & 43 & 32 \\
\hline
\end{tabular}


Table 3. Different plant growth promoting activities of PGPR isolates; P-solubilizing activities, $\mathrm{N}$-fixing activities, K-solubilizing activities, IAA, Siderophore, Ammonia and HCN production.

\begin{tabular}{ccccccccc}
\hline No. & Isolates & $\mathrm{N}$ & $\begin{array}{c}\mathrm{P} \\
(\mathrm{PSI})\end{array}$ & $\begin{array}{c}\mathrm{K} \\
(\mathrm{KSI})\end{array}$ & $\begin{array}{c}\text { IAA } \\
(\mu \mathrm{g} / \mathrm{ml})\end{array}$ & Siderophore & Ammonia & HCN \\
\hline 1 & B3 & +++ & 3.07 & - & 19.15 & ++ & +++ & - \\
2 & S2 & +++ & 2.4 & - & 6.69 & ++ & +++ & - \\
3 & S3 & +++ & 2.86 & - & 4.77 & +++ & ++ & - \\
4 & S4 & ++ & 2.3 & - & 8.23 & ++ & +++ & - \\
5 & BP2 & - & 2.56 & - & 8.86 & +++ & +++ & - \\
6 & BP3 & - & 2.2 & - & 15.36 & ++ & + & - \\
7 & W1 & - & 2.7 & - & 51.00 & ++ & +++ & - \\
8 & W5 & - & 2.21 & - & 10.83 & ++ & + & - \\
9 & M1 & - & 4.33 & - & 4.14 & + & ++ & - \\
10 & TK1 & - & 2.1 & 4.2 & 5.94 & ++ & ++ & ++ \\
11 & TK6 & - & 3.88 & 3.75 & 9.92 & + & ++ & - \\
12 & SAK6 & - & 3.85 & 3 & 5.08 & +++ & ++ & +++ \\
13 & SuK2 & - & 2.03 & 2.42 & 2.82 & ++ & +++ & - \\
14 & WK5 & - & - & 2 & 1.96 & + & +++ & - \\
15 & M2 & - & 5.67 & 3.8 & 5.78 & + & ++ & - \\
\hline
\end{tabular}

$-=$ not detected, $+=$ low production, $++=$ moderate production, $+++=$ high production .

The potassium solubilizing activities of the isolates were tested by incubating them on Aleksandrow's media. Among 32 bacterial strains, 6 were seen to have potassium solubilizing activity on Aleksandrow's media plates. Here the potassium solubilization index was obtained by formula: $\mathrm{SI}=$ Colony diameter $+\mathrm{Di}-$ ameter of zone/colony Diameter. KSB isolates such as TK1, TK6, SAK6, SuK2, WK5 and M2 strains have high potassium solubilizing activities (Table 3). They were found to possess phosphate solubilisation activities when they were inoculated on PVK media. Most of the isolates were able to produce phosphate solubilizing activity. Our results are in agreement with those studies, i.e. Silva et al. found that $90 \%$ of the isolates were positive for phosphate solubilisation while Oteino et al. reported that $75 \%$ of the isolates were phosphate solubilizers [25] [26].

IAA Production Activity. About $80 \%$ of the rhizospheric bacteria are able to produce IAA. L-tryptophan is considered as a precursor of IAA production when tryptophan is added to the bacterial culture media. Plant root exudates are natural source of L-tryptophan to enhance auxin biosynthesis in the plant root zone where rhizosphere microflorea are inhibited [27]. Several PGPRs for the genera Azospirillum, Azotobacter, Bacillus, Burkholderia, Enterobacter, Pantoea and Pseudomonas have been reported for the production of IAA in the presence of tryptophan as a precursor [28]. All the selected 15 isolates are observed to accumulate plant defense hormone IAA. The lower IAA producer strains were $\mathrm{WK} 5$, SuK2, S3 and M1 while the higher IAA producers were $\mathrm{W} 1, \mathrm{~B} 3, \mathrm{BP} 3$ and $\mathrm{W} 5$ as shown in Table 3. IAA production was found $51 \mu \mathrm{g} / \mathrm{ml}$ by the isolate $\mathrm{W} 1$ 
which was the highest amount in all PGPR isolates being analysed.

Production of Biocontrol Agents. Siderophore produced by PGPR is one of the biocontrol properties against pathogenic microbes in iron limiting condition. PGPRs can produce a certain amount of siderophore which have a considerable high affinity for iron [19]. Although all the selected isolates are seen to produce iron-chelating substance, siderophore, S3 and BP2 are the two strains with highest siderophore productivity. Another important trait of the PGPR is the production of ammonia (plants can use ammonia as a nitrogen source) which impacts directly the growth of the plants.

The ammonia producing activity is an indicator for the process of ammonification which takes place in the rhizosphere rather than non-rhizosphere [3]. Ammonia and $\mathrm{HCN}$ are considered as indirect mechanisms of the plant growth development. In this study, ammonia production was observed in all 15 selected bacterial strains. HCN production from rhizobacteia is also essential to play an important role in the biological control of pathogenic microorganisms [29]. When the bacterial isolates were subjected to $\mathrm{HCN}$ production assay, only TK1 and SAK6 were found to be efficient hydrogen cyanide producers. SAK6 produced higher HCN than TK1 strains according to the screening of Feigl-Anger paper method.

Hydrolytic Enzymes Production. Hydrolytic enzymes are the agents for prevention of plant diseases by pathogenic microorganisms in the close vicinity of the plants. They have the ability to secrete elevated level of lytic enzymes such as chitinase, glucanase, etc. from the cell wall [24]. Almost all the selected bacterial isolates were seen to produce chitinase and $\beta$-glucanase enzyme. It is found from Table 4 that the strain TK6 did not produce chitinase while BP3 could not produce $\beta$-glucanase. Furthermore, S4, BP3, M1 and M2 strains could not produce amylase enzyme while B3, W1 and WK5 produced highest amount of it. In another comparison, B3, BP2 and WK5 produced highest amount of cellulase in vitro, S2, M1 and M2 were not able to produce cellulase. Similarly, it is observed that S2, M1, TK1, SAK6 and M2 could not produce pectinase e while the other 10 strains produce a minor amount of this enzyme (Table 4) (Figure 1, Figure 2).

Antagonistic Activity of the PGPR Isolates. All the selected PGPR isolates were tested for antibacterial activity against Xanthomonas campestric when the inhibition zone was taken as an indicator for their antibacterial properties using agar well diffusion method. Among the isolates analysed, B3, S4, TK1, SAK6 and SuK2 showed positive results. The best antibacterial activity was found to be B3 which has the inhibition zone diameter as $4 \mathrm{~cm}$, followed by the isolate S4 with 2 $\mathrm{cm}$ of it. The other two isolates have the inhibition zone diameter around $1.5 \mathrm{~cm}$ as shown in Table 5. Opposition assay was used to determine the antifungal activity against Fusarium oxisporum, Phythium sp., Rhizoctonia solani using dual culture plate method. Among them, only two isolates TK1 and SAK6 showed anifungal activities. TK1 showed inhibition activity against $R$. solani and Phythium sp. while SAK6 showed antagonistic to the two fungal pathogens namely $F$. oxisporum and $R$. solani (Table 6). Both isolates have the ability to produce 
$\mathrm{HCN}$. Furthermore, it was found that $\mathrm{HCN}$ produced by the above isolates were able to suppress the growth of phytopathogenic fungi such as Fusarium oxisporum, Rhizoctonia solani and Phythium sp.
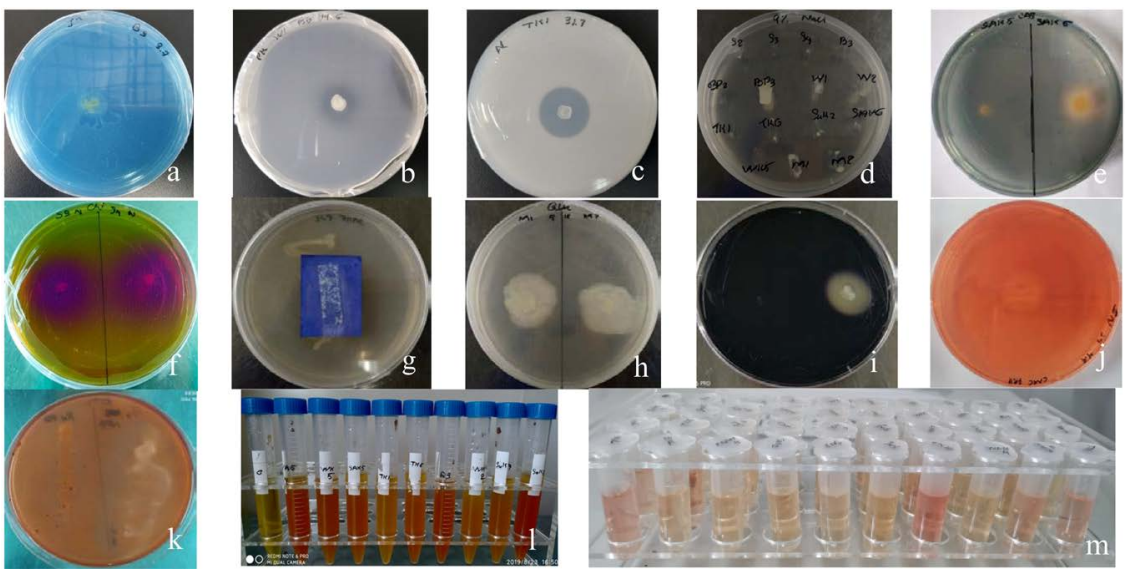

Figure 1. (a) Screening of nitrogenase enzyme activity, (b) Phosphate solubilisation activity, (c) potassium solubilisation activity, (d) Salt stress tolerance of PGPR strains on $9 \% \mathrm{NaCl}$, (e) Siderophore production, (f) Chitinase enzyme production, (g) HCN production, (h) Glucanase enzyme production, (i) Amylase enzyme production, (j) Cellulase enzyme production, (k) Pectinae enzyme production, (l) Ammonia production, (m) IAA production.

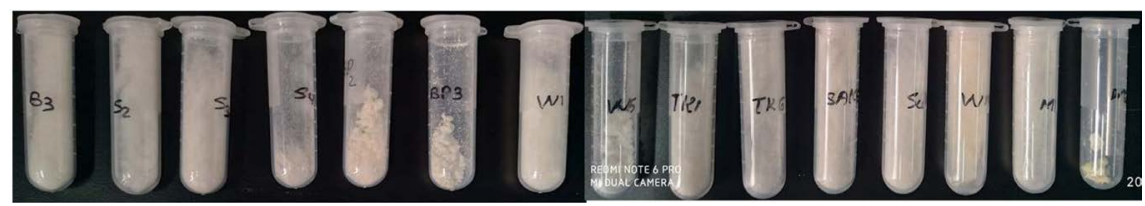

Figure 2. Freeze-drying of the selected 15 PGPR isolates.

Table 4. Hydrolytic enzyme productions of 15 PGPR isolates.

\begin{tabular}{|c|c|c|c|c|c|c|}
\hline No. & Isolates & Amylase & Cellulase & Pectinase & Chitinase & $\beta$-Glucanase \\
\hline 1 & B3 & +++ & +++ & + & +++ & +++ \\
\hline 2 & $\mathrm{~S} 2$ & + & - & - & ++ & ++ \\
\hline 3 & S3 & + & + & + & +++ & +++ \\
\hline 4 & $\mathrm{~S} 4$ & - & ++ & + & +++ & +++ \\
\hline 5 & BP2 & ++ & +++ & + & ++ & + \\
\hline 6 & BP3 & - & + & + & ++ & - \\
\hline 7 & $\mathrm{~W} 1$ & +++ & + & + & ++ & + \\
\hline 8 & W5 & ++ & + & + & ++ & ++ \\
\hline 9 & M1 & - & - & - & +++ & ++ \\
\hline 10 & TK1 & + & + & - & ++ & ++ \\
\hline 11 & TK6 & + & + & + & - & + \\
\hline 12 & SAK6 & + & + & - & +++ & + \\
\hline 13 & SuK2 & + & + & + & ++ & + \\
\hline 14 & WK5 & +++ & +++ & + & +++ & +++ \\
\hline 15 & M2 & - & - & - & +++ & ++ \\
\hline
\end{tabular}

$-=$ not detected, $+=$ low production, $++=$ moderate production, $+++=$ high production . 
Table 5. Antagonism assay of PGPR isolates against plant pathogenic bacteria Xanthomonas campestric.

\begin{tabular}{|c|c|c|}
\hline No. & Isolates & Zone of Inhibition $(\mathrm{cm})$ \\
\hline 1 & B3 & 4 \\
\hline 2 & S2 & - \\
\hline 3 & S3 & - \\
\hline 4 & S4 & 2 \\
\hline 5 & BP2 & - \\
\hline 6 & BP3 & - \\
\hline 7 & W1 & - \\
\hline 8 & W5 & - \\
\hline 9 & M1 & - \\
\hline 10 & TK1 & 1.4 \\
\hline 11 & TK6 & - \\
\hline 12 & SAK6 & 1.55 \\
\hline 13 & SuK2 & 1.5 \\
\hline 14 & WK5 & - \\
\hline 15 & M2 & - \\
\hline
\end{tabular}

Table 6. Antagonism assay of PGPR isolates against phytopathogenic fungi.

\begin{tabular}{cccc}
\hline PGPR & \multicolumn{3}{c}{ Antagonism against Phytopathogenic fungi } \\
\cline { 2 - 4 } isolates & $\begin{array}{c}\text { Rhizoctonia } \\
\text { solani }\end{array}$ & $\begin{array}{c}\text { Phythium } \\
\text { sp. }\end{array}$ & $\begin{array}{c}\text { Fusarium } \\
\text { oxisporum }\end{array}$ \\
\hline B3 & - & - & - \\
S2 & - & - & - \\
S3 & - & - & - \\
S4 & - & - & - \\
BP2 & - & - & - \\
BP3 & - & - & - \\
W1 & - & - & - \\
W5 & - & - & - \\
M1 & - & - & - \\
TK1 & + & - & - \\
TK6 & - & - & - \\
SAK6 & - & - & - \\
SuK2 & - & - & - \\
WK5 & - & - & - \\
M2 & - & - & - \\
\hline
\end{tabular}

- = not inhibition, $+=$ inhibition. 
Salt Tolerance Activity. Salinity is a major agricultural problem in many countries around the world, particularly in the arid and semi-arid regions. [30] Salinity affects plant development in almost all aspects including seed germination, vegetative growth and even reproductive development. It imposes ion toxicity, plant nutrient deficiency, osmotic stress and oxidative stress in plants, these can cause limitation of water uptake from the soil. The ability of the bacterial isolates to withstand high salt concentration became a unique feature to facilitate competitiveness in the soil ecosystem, especially in the rhizosphere which is the only place for these isolates to grow effectively. Zerihun Tsegaye and his colleagues reported that $13.5 \%$ of the tested isolates (E. cloacae ss disolvens, $V$. sediminis, $C$. amlonaticus, $P$. corrugata, $K$. oxytoca and B. cereus) possessed the ability to tolerate $5 \% \mathrm{NaCl}[10]$. In this study, 15 isolates were evaluated for salt stress tolerance. It was observed that all the isolates were able to grow at salt concentration $(\mathrm{NaCl})$ at $5 \%$. Most of them were able to tolerate at $7 \% \mathrm{NaCl}$ except the isolates B3, S4 and BP2. However, when the concentration reached to $9 \%$, only $\mathrm{BP} 3, \mathrm{~W} 1, \mathrm{M} 1$ and M2 strains were observed to grow at this high salt concentration (Table 7).

Table 7. Growth of PGPR isolates under different salt concentration.

\begin{tabular}{|c|c|c|c|c|c|c|c|c|c|}
\hline \multirow{2}{*}{ Isolates } & \multicolumn{9}{|c|}{ Salt Concentration $(\mathrm{NaCl} \%)$} \\
\hline & $1 \%$ & $2 \%$ & $3 \%$ & $4 \%$ & $5 \%$ & $6 \%$ & $7 \%$ & $8 \%$ & $9 \%$ \\
\hline B3 & ++ & ++ & ++ & ++ & ++ & - & - & - & - \\
\hline S2 & ++ & ++ & ++ & ++ & ++ & ++ & ++ & - & - \\
\hline S3 & ++ & ++ & ++ & ++ & ++ & ++ & ++ & - & _- \\
\hline S4 & ++ & ++ & ++ & ++ & ++ & - & - & - & - \\
\hline BP2 & ++ & ++ & ++ & ++ & + & - & - & - & - \\
\hline BP3 & ++ & ++ & ++ & ++ & ++ & ++ & ++ & + & + \\
\hline W1 & ++ & ++ & ++ & ++ & ++ & ++ & ++ & + & + \\
\hline W5 & ++ & ++ & ++ & ++ & ++ & ++ & ++ & + & - \\
\hline TK1 & ++ & ++ & ++ & ++ & + & + & + & - & - \\
\hline TK6 & ++ & ++ & ++ & ++ & ++ & ++ & ++ & - & - \\
\hline SAK6 & ++ & ++ & ++ & ++ & ++ & ++ & ++ & - & - \\
\hline SuK2 & ++ & ++ & ++ & ++ & ++ & ++ & ++ & - & - \\
\hline WK5 & ++ & ++ & ++ & ++ & ++ & ++ & ++ & - & - \\
\hline M1 & ++ & ++ & ++ & ++ & ++ & ++ & ++ & + & + \\
\hline M2 & ++ & ++ & ++ & ++ & ++ & ++ & ++ & + & + \\
\hline
\end{tabular}

$-=$ no growth, $+=$ weak growth,$++=$ strong growth . 
Molecular Characterization of Selected Bacterial Isolates. Microscopic examination of the isolates was shown in Figure 3. Sequence analysis of $16 \mathrm{~S}$ rRNA gene sequences (Figure 4) were performed the results comparisons with the available sequences were performed by (BLAST) of NCBI, USA database. The direct sequencing of amplified PCR products was scored the maximum identities of $97 \%$ to $100 \%$ homology in molecular identification of growth promoting bacteria. The strains are determined in such a way, B3 as Pseudomonas plecoglossicida, S2 as Stenotrophomonas maltophilia, S3 as Achromobacter insolitus, S4 as Pseudomonas aeruginosa, BP2 as Chryseobacterium hispalense, BP3 as Bacillus pumilus, W1 as Enterobacter hormaechei, W5 as Comamonas testosteroni, TK1 as Enterobacter roggenkampii, TK6 as Delftia acidovoran, SAK6 as Pseudomonas putida, SuK2 as Agrobacterium fabrum, WK5 as Flavobacterium anhuiense, M1 and M2 as Acinetobacter soli. The sequences of the $16 \mathrm{~S}$ rDNA of the 15 isolates were submitted to NCBI database and the resulting accession number were assigned those strains (Table 8). Although rhizobacteria are largely represented by the species of Pseudomonas and Bacillus genus, many authors [27] reported that some bacteria belonging to the family of Enterobacteriaceae such as Serratia, Pantoea and Enterobacter strains found in the area of the rhizoplane of leguminous plants.

Table 8. Closest relatives (BLAST search) of selected PGPR strains.

\begin{tabular}{|c|c|c|c|c|c|}
\hline $\begin{array}{l}\text { Isolate } \\
\text { ID }\end{array}$ & Isolation Source & $\begin{array}{c}\text { 16s rDNA fragment } \\
\text { length }\end{array}$ & Genus/Species & $\begin{array}{l}\text { Similarity } \\
\%\end{array}$ & $\begin{array}{l}\text { Gene Bank } \\
\text { accession no. }\end{array}$ \\
\hline B3 & Bean rhizosphere & $1036 \mathrm{bp}$ & Pseudomonas plecoglossicida & $99 \%$ & MT071410.1 \\
\hline S2 & Sugarcane rhizosphere & $1080 \mathrm{bp}$ & Stenotrophomonas maltophilia & $99 \%$ & MT071411.1 \\
\hline S3 & Sugarcane rhizosphere & $1326 \mathrm{bp}$ & Achromobacter insolitus & $99 \%$ & MT071413.1 \\
\hline S4 & Sugarcane rhizpsphere & $1006 \mathrm{bp}$ & Pseudomonas aeruginosa & $99 \%$ & MT071414.1 \\
\hline BP2 & Bean rhizosphere & $985 \mathrm{bp}$ & Chryseobacterium hispalense & $96 \%$ & MT071416 \\
\hline BP3 & Bean rhizosphere & $992 \mathrm{bp}$ & Bacillus pumilus & $99 \%$ & MT071417.1 \\
\hline W1 & Watermelon rhizosphere & $1060 \mathrm{bp}$ & Enterobacter hormaechei & $98 \%$ & MT138532 \\
\hline W5 & Watermelon rhizosphere & $933 \mathrm{bp}$ & Comamonas testosteroni & $95 \%$ & MT084591.1 \\
\hline TK1 & Tomato rhizosphere & $1378 \mathrm{bp}$ & Enterobactercloacae & $98 \%$ & MN971613 \\
\hline TK6 & Tomato rhizosphere & 1009 bp & Delftia acidovoran & $97 \%$ & MT071421.1 \\
\hline SAK6 & Sugarcane rhizosphere & $1059 \mathrm{bp}$ & Pseudomonas putida & $99 \%$ & MT071425.1 \\
\hline SuK2 & Sugarcane rhizosphere & 1017 bp & Agrobacterium fabrum & $100 \%$ & MT075608.1 \\
\hline WK5 & Watermelon rhizosphere & $973 \mathrm{bp}$ & Flavobacterium anhuiense & $94 \%$ & MT071437.1 \\
\hline M1 & Mangrove rhizosphere & $1103 \mathrm{bp}$ & Acinetobacter soli & $98 \%$ & MT071438.1 \\
\hline M2 & Mangrove rhizosphere & $1060 \mathrm{bp}$ & Acinetobacter soli & $99 \%$ & MN989017.1 \\
\hline
\end{tabular}



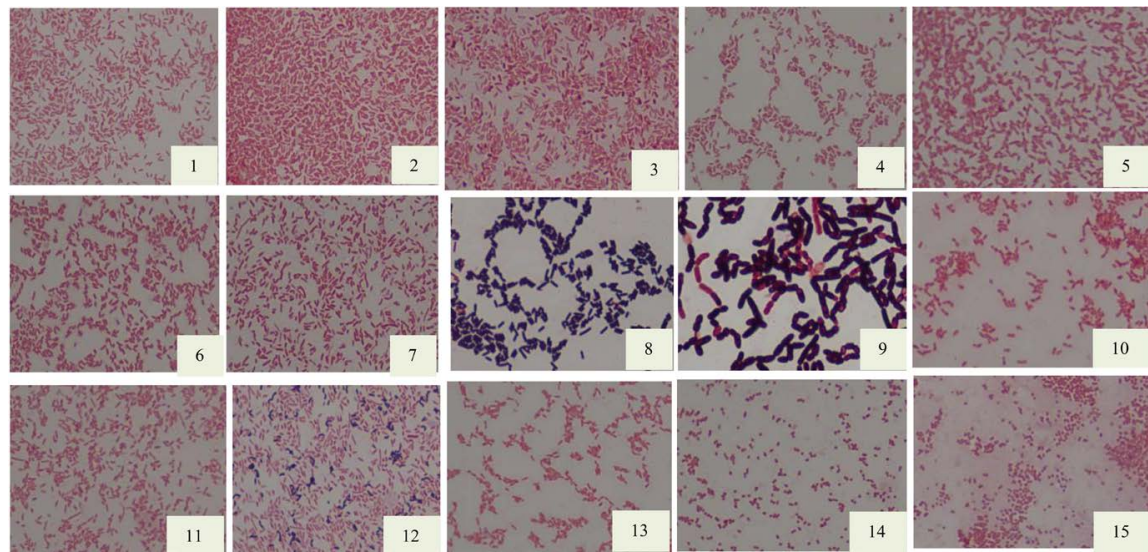

Figure 3. Microscopic morphology of 15 PGPR isolates: $1=\mathrm{B} 3,2=\mathrm{S} 2,3=\mathrm{S} 3,4=\mathrm{S} 4,5=$ BP2, $6=\mathrm{BP} 3,7=\mathrm{W} 1,8=\mathrm{W} 5,9=\mathrm{TK} 1,10=\mathrm{TK} 6,11=\mathrm{SuK} 2,12=\mathrm{SAK} 6,13=\mathrm{WK} 5,14$ $=\mathrm{M} 1,15=\mathrm{M} 2$.

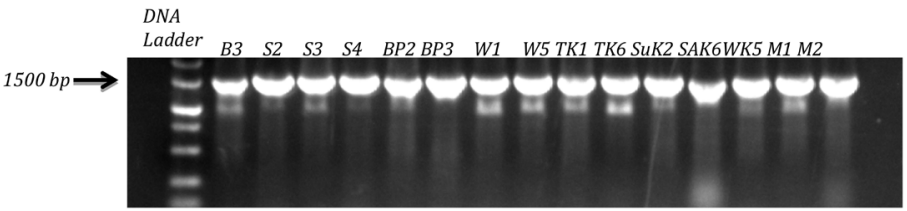

Figure 4. Gel electrophoresis of $16 \mathrm{~S}$ rRNA gene fragments of 15 PGPR isolates.

Seed Germination Bioassay. The seeds are generally the reproductive parts of the plants. Lugtenberg and his colleagues reported that the use of bacterial inoculants is able to increase plant growth and germination rate, improve seedling emergence, protect plants from certain disease and resist environmental stress [7]. Seed germination was improved by the application of PGPR in Crataehus pseudoheterophylla [27]. In this study, the abilities of selected PGPR isolates (B3, S3, W1, TK1, SAK6 and M2) were tested to evaluate the seedling development of green-gram and maize (Figure 5). The parameters for the germination analysis were seed vigor index, number of root and seedling fresh weights. In green-gram germination experiment, the seed vigor indexes were no significantly difference in all the bacterial treatments individually, in consortium, with positive and negative controls. The highest vigor index was observed in the treatment with S3 isolate. The lowest was W1 which was even lower than control. In maize, there was no significant different among the treatments. It can be seen that the results were almost the same as that in the green-gram experiment (Figure 6). In root formation parameter, there were no significant difference in both green-gram and maize. All the treatments including control were in the same group. The best bacterial treatment for root formation was W1 in green-gram. W1 strain gave the highest IAA production in vitro. The lowest root formation was found in S3. However in maize, the highest root formation was found in the treatment with bacterial isolate S3 and the lowest was found in control (Figure 7).

In fresh weight parameter, there was no significant difference in both crops. The highest fresh weight was found in green-gram with the treatments of B3. 
The lowest result was found in M2 treatment. The treatment with isolate S3 gave the best result in maize and the lowest was observed in control (Figure 8). This is due to the actual composition of the microbial community in the root zone depends on such a specific root type, plant species, plant nature and type [24]. All the resulting PGPR isolates were seen to be able to exhibit more than eight/nine PGP traits. This is in agreement with the report in the literature that PGPR strains are able to express multiple plant growth promoting activities [23]. The bacterial isolates with two or more PGP traits can promote plant growth directly or indirectly or synergistically.

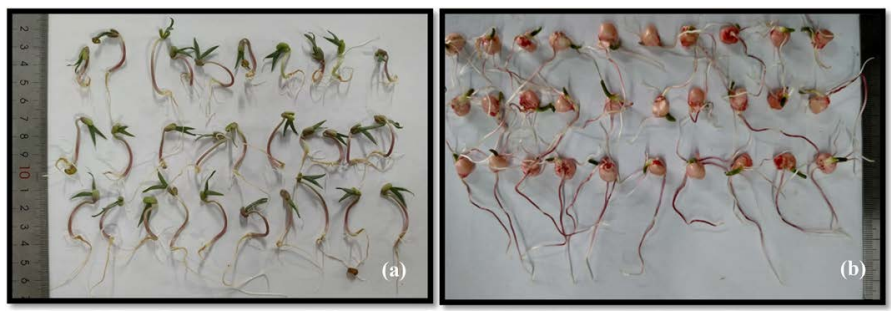

Figure 5. Germination test of PGPR treatments in Greengram (a) and Maize (b).
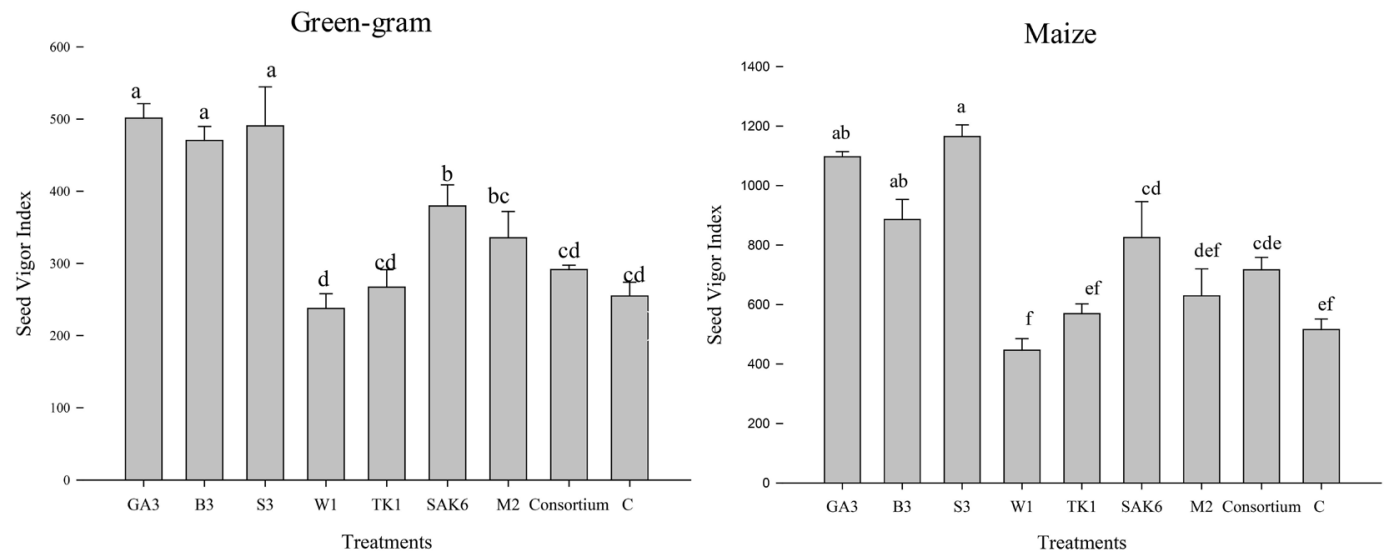

Figure 6. Comparison of the effects of six bacterial isolates, bacterial consortium, GA3 (positive control) and water (negative control) on the germination of green-gram and maize.
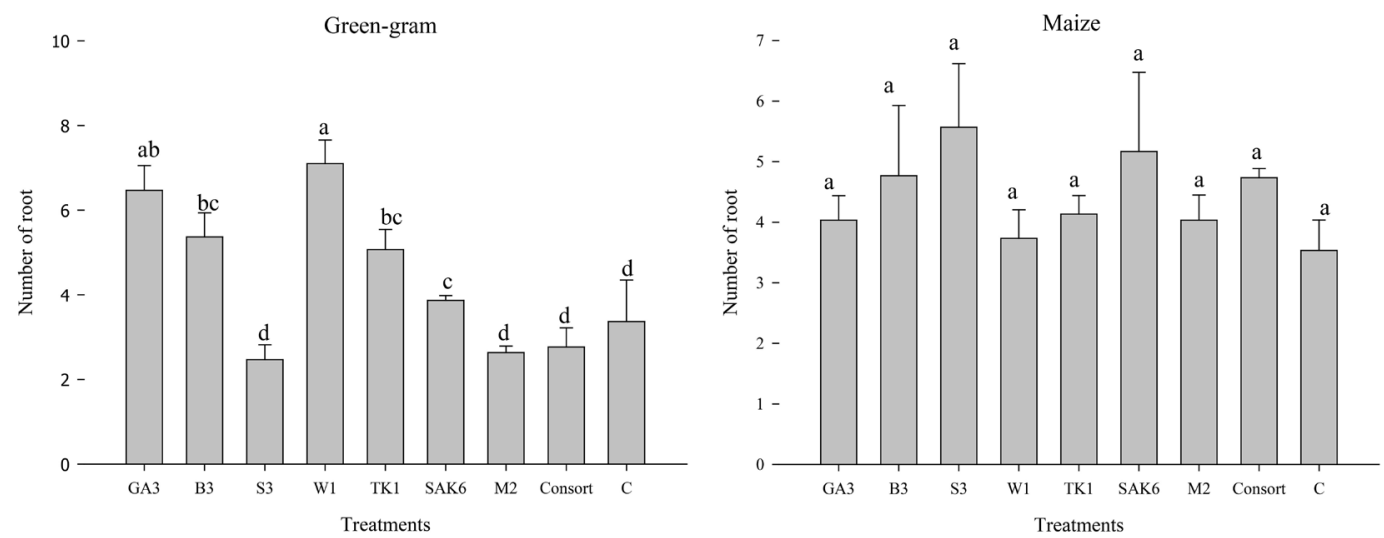

Figure 7. Comparison of the effects of six bacterial isolates, bacterial consortium, GA3 (positive control) and water (negative control) on the root formation of green-gram and maize. 

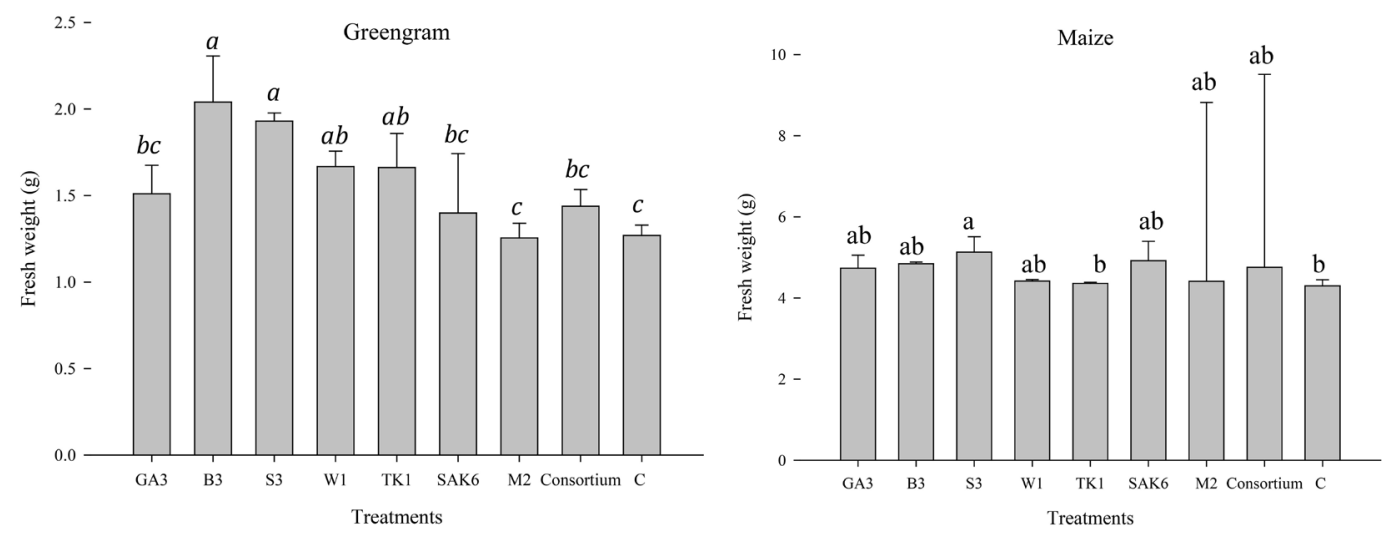

Figure 8. Comparison of the effects of six bacterial isolates, bacterial consortium, GA3 (positive control) and water (negative control) on the fresh weights of green-gram and maize.

\section{Conclusion}

In this study, 15 isolates from crop fields were screened for their PGP activities. All the PGPR isolates have multifunctional activities for plant growth promotion and production of extracellular hydrolytic enzymes. Among them, 6 bacterial isolates showing the most prominent activities in PGP traits were tested on seed germination, root formation and fresh weight of green-gram and maize. Based on the results, the currently isolated bacterial strains especially Pseudomonas plecoglossicida B3 strain and Acromobacter insolitus S3 strain could be useful for bio-fertilizer individually or as a consortium in order to be used for an alternative approach to chemical fertilizers. Further studies are needed to develop certain formulations for the large scale commercial application in various crop field uses.

\section{Acknowledgements}

All the authors are thankful to the financial support by the Research Start-Up Funds from Hainan University in China (KYQD_ZR2017212). KTO is grateful for the support by Talented Young Scientists Program, China Ministry of Science and Technology.

\section{Conflicts of Interest}

The authors declare no conflicts of interest regarding the publication of this paper.

\section{References}

[1] Adediran, J.A., Taiwo, L.B., Akande, M.O., Sobulo, R.A. and Idowu, O.J. (2004) Application of Organic and Inorganic Fertilizer for Sustainable Maize and Cowpea Yields in Nigeria. Journal of Plant Nutrition, 27, 1163-1181. https://doi.org/10.1081/PLN-120038542

[2] Karlidag, H., Esitken, A. and Turan, M. (2007) Effects of Root Inoculation of Plant Growth Promoting Rhizobacteria on Yield Growth and Nutrient Element Content of Leaves of Apple. Scientia Horticulturae, 114, 16-20. 
https://doi.org/10.1016/j.scienta.2007.04.013

[3] Joseph, B. and Lawrence, P.R. (2007) Characterization of Plant Growth Promoting Rhizobacteria Associated with Chickpea (Cicer arietinum L). International Journal of Plant Production, 1, 141-152.

[4] Dastager, S.G., Deepa, C.K. and Pandey, A. (2011) Potential Plant Growth Promoting Activity of Serratia nematodiphila NII-0928 on Black Pepper. World Journal of Microbiology and Biotechnology, 27, 259-265. https://doi.org/10.1007/s11274-010-0454-Z

[5] Antoun, H. and Kloepper, J.W. (2001) Plant Growth Promoting Rhizobacteria (PGPR). In: Brenner, S. and Miller, J.H., Eds., Encyclopedia of Genetics, Academic Press, New York, 1477-1480. https://doi.org/10.1006/rwgn.2001.1636

[6] de Freitas, J.R., Banerjee, M.R. and Germida, J.J. (1997) Phosphate-Solubilizing Rhizobacteria Enhance the Growth and Yield But Not Phosphorus Uptake of Canola (Brassica napus L.). Biology and Fertility of Soils, 24, 358-364. https://doi.org/10.1007/s003740050258

[7] Lugtenberg, B., Chin-A-Woeng, T. and Bloemberg, G. (2002) Microbe-Plant Interactions: Principles and Mechanisms. Antonie van Leeuwenhoek, 81, 373-383. https://doi.org/10.1023/A:1020596903142

[8] Turner, S., Pryer, K.M., Miao, V.P.W. and Palmer, J.D. (1999) Investigating Deep Phylogenetic Relationships among Cyanobacteria and Plastids by Small Subunit rRNA Sequence Analysis. Journal of Eukaryotic Microbiology, 46, 327-338. https://doi.org/10.1111/j.1550-7408.1999.tb04612.x

[9] Grobelak, A.N., Kacprzak, M., et al. (2015) Using Plant Growth-Promoting Rhizobacteria (PGPR) to Improve Plant Growth. Ecological Engineering, 84, 22-28. https://doi.org/10.1016/j.ecoleng.2015.07.019

[10] Tsegaye, Z., Gizaw, B., Tefera, G., Feleke, A., Chaniyalew, S., Alemu, T. and Assefa, F. (2019) Isolation and Biochemical Characterization of Plant Growth Promoting (PGP) Bacteria Colonizing the Rhizosphere of Tef Crop During the Seedling Stage. Journal of Plant Science and Phytopathology, 3, 13-27. https://doi.org/10.26717/BJSTR.2019.14.002534

[11] Lugtenberg, B.J., Chin-A-Woeng, T.F. and Bloemberg, G. (2002) Microbe-Plant Interactions: Principles and Mechanisms. Antonie van Leeuwenhoek, 81, 373-383. https://doi.org/10.1023/A:1020596903142

[12] Pikovskaya, R.I. (1948) Mobilization of Phosphorus in Soil in Concentration with Vital Activity of Some Microbial Species. Microbiology, 17, 362-337.

[13] Glickmann, E. and Dessaux, Y. (1995) A Critical Examination of the Specificity of the Salkowski Reagent for Indolic Compounds Produced by Phytopathogenic Bacteria. Applied and Environmental Microbiology, 61, 793-796. https://doi.org/10.1128/AEM.61.2.793-796.1995

[14] Capuccino, J.C. and Sherman, N. (2001) Microbiology: A Laboratory Manual. 6th Edition, Benjamin-Cummings Pub. Co., San Francisco, 491-496.

[15] Schwyn, B. and Neilands, J.B. (1987) Universal Chemical Assay for the Detection and Determination of Siderophores. Analytical Biochemistry, 160, 47-56. https://doi.org/10.1016/0003-2697(87)90612-9

[16] Collins, C.H., Grange, J.M., et al. (2004) Microbiological Methods. Hodder \& Stoughton Ltd., London.

[17] Anand, A.A., Sankar, S.G., et al. (2010) Isolation and Characterization of Bacteria from the Gut of Bombyx mori That Degrade Cellulose, Xylan, Pectin and Starch 
and Their Impact on Digestion. Journal of Insect Science, 10, 1-20. https://doi.org/10.1673/031.010.10701

[18] Wood, D.A., Dudley, K.J., et al. (1988) Cellulase Production in the Life Cycle of the Cultivated Mushroom Agaricus bisporus. In: Aubert, J.P., Ed., FEMS Symposium, Biochemistry and Genetics of Cellulose Degradation, Academic Press, Cambridge, $1-53$.

[19] Whipps, J.M. (2001) Microbial Interactions and Biocontrol in the Rhizosphere. Journal of Experimental Botany, 52, 487-511. https://doi.org/10.1093/jxb/52.suppl 1.487

[20] Sambrook, J. and Russell, D.W. (2001) Molecular Cloning: A Laboratory Manual. Cold Spring Harbor Laboratory Press, New York.

[21] Lamy, B., Verdier, I., Decousser, J.W., Lecaillon, E., Marchandin, H., Roger, F., Tigaud, S., de Montclos, H., Kodjo, A., et al. (2010) Accuracy of 6 Commercial Systems for Identifying Clinical Aeromonas Isolates. Diagnostic Microbiology and Infectious Disease, 67, 9-14. https://doi.org/10.1016/j.diagmicrobio.2009.12.012

[22] Razmi, Z., Hamidi, R. and Pirasteh-Anosheh, H. (2013) Seed Germination and Seedling Growth of Three Sorghum (Sorghum bicolor L.) Genotypes as Affected by Low Temperatures. International Journal of Farming and Allied Sciences, 2, 851-856.

[23] Joseph, B., Patra, R.R. and Lawrence, R. (2007) Characterization of Plant Growth Promoting Rhizobacteria Associated with Chickpea (Cicer arietinum L). International Journal of Plant Production, 1, 141-152.

[24] Ai'shah, O.N., Keng, C.L., Othman, A., et al. (2009) Influence of Various Combinations of Diazotrophs and Chemical N Fertilizer on Plant Growth and $\mathrm{N}_{2}$ Fixation Capacity of Oil Palm Seedlings (Elaeis guineensis Jacq.). Thai Journal of Agricultural Science, 42, 139-149.

[25] Silva, K., et al. (2016) Diversity and Capacity to Promote Maize Growth of Bacteria Isolated from the Amazon Region. Acta Amazonica, 46, 111-118. https://doi.org/10.1590/1809-4392201502502

[26] Oteino, N., et al. (2015) Plant Growth Promotion Induced by Phosphate Solubilizing Endophytic Pseudomonas Isolates. Frontiers in Microbiology, 6, 1-9. https://doi.org/10.3389/fmicb.2015.00745

[27] Ahmadloo, F., Tabari, M., Azadi, P. and Hamidi, A. (2014) Effect of Plant Growth Promoting Rhizobacteria (PGPRs) and Stratification on Germination Traits of Crataegus pseudoheterophylla Pojark. Scientia Horticulturae, 172, 61-67. https://doi.org/10.1016/j.scienta.2014.03.049

[28] Tsavkelova, E.A., Cherdyntseva, T.A., Botina, S.G. and Netrusov, A.I. (2007) Bacteria Associated with Orchid Roots and Microbial Production of Auxin. Microbiological Research, 162, 69-76. https://doi.org/10.1016/j.micres.2006.07.014

[29] Singh, R., Kumar, A., et al. (2017) PGPR Isolates from the Rhizosphere of Vegetable Crop Momordica charantia: Characterization and Application as Biofertilizer. International Journal of Current Microbiology Applied Science, 6, 1789-1802. https://doi.org/10.20546/ijcmas.2017.603.205

[30] Kloepper, J.W., Leong, J., Teintze, M. and Scrhorth, M.N. (1980) Enhanced Plant Growth by Siderophores Produced by Plant Growth-Promoting Rhizobacteria. Nature, 286, 885-886. https://doi.org/10.1038/286885a0 